\title{
Peanut Oil
}

National Cancer Institute

\section{Source}

National Cancer Institute. Peanut Oil. NCI Thesaurus. Code C66332.

The edible oil extracted from peanuts. Peanut oil is used primarily as a cooking oil and as a food ing redient. 